\title{
Student Perceptions of Faculty of Medicine, Dentistry, Nursing, and Pharmacy University of Indonesia in Facing Disaster as Efforts to Enhance Resilience in University 2017
}

\section{Fiori Amelia Putri ${ }^{1}$ and Fatma Lestari ${ }^{1,2}$}

${ }^{1}$ Occupational Health and Safety Department, Faculty of Public Health, Universitas Indonesia, J. Margonda Raya, Beji, Pondok Cina, Kota Depok, Jawa Barat 16424, Indonesia ${ }^{2}$ Integrated Laboratory and Research Center University of Indonesia, Jl. Margonda Raya, Beji, Pondok Cina, Kota Depok, Jawa Barat 16424, Indonesia

\section{Abstract}

University is one of the institutions that may have to face disaster events. For two decades, there have been a number of disasters that have negatively impacted the university. Resilience is an important concept that has been developed in the field

Corresponding Author: Fatma Lestari

fatma@ui.ac.id

Received: 15 May 2018 Accepted: 3 June 2018 Published: 19 June 2018

Publishing services provided by Knowledge $\mathrm{E}$

(c) Fiori Amelia Putri and Fatma Lestari. This article is distributed under the terms of the

Conons Attribution License,

which permits unrestricted use and redistribution provided that the original author and source are credited.

Selection and Peer-review under the responsibility of the ICOHS 2017 Conference Committee.

\section{G OPEN ACCESS} of disaster management. This concept emphasizes on building adaptive capacity through social development, community competences, and strong communication and information systems. Students as a community often stay in campus for their activities such as study, research, and organization activities and are therefore prone to risks and dangers. It is important for students to be prepared in facing possible disasters so as to increase the resilience in the event of a disaster in the university. This research will show the perception of students in facing disaster, and furthermore will develop comprehensive disaster mitigation at the university, not only structural resilience, but also human resource to prepare in facing disasters. The purpose of this study is to describe the preparedness and awareness of the students of the Faculty of Medicine, Faculty of Dentistry, Faculty of Nursing, and Faculty of Pharmacy of the University of Indonesia in facing disasters in an effort to increase disaster resilience in the university. This is a quantitative cross-sectional study performed on 388 respondents. Results show that generally the respondents are resilient enough in facing disasters. It showed from their answers with a percentage $>50 \%$, there are: awareness of potentials for disaster on campus, respondents need to prepare in facing disasters, they got information from valid sources, they have been trained in disaster, appropriate answers regarding to emergency response during disaster, and knowledge regarding nearest health services. However, improvements are still needed for several variables, including disaster preparedness on campus, knowledge of early warning system in campus, ownership of catastrophe insurance, level of preparedness (which is still low at 30.9\%), valid information sources, and participation in disaster response training should be increased.

Keywords: disaster, disaster management, awareness, preparedness, resilience, university 


\section{Introduction}

Disaster is a very detrimental event that can interfere with the function of a community or society and causes harms to both human, materials, economics, and environment that exceeds human's ability to cope using its own resources. Indonesia is known as the ring of fire, which is geographically very vulnerable to disasters. Referring to data from the National Disaster Management Agency (Badan Nasional Penanggulangan Bencana, BNPB), the number of disasters in Indonesia in 2015 and 2016 reaches 1,677 and 1,985, respectively, with 375 people were killed, 383 were injured, 52 million suffered and were displaced, and more than 34 thousand houses were damaged. Based on Indonesia's disaster statistics over the last three years (2013-2016), the recorded disaster events include floods (32\%); tornados (30.2\%); landslides (26.1\%); forest and land fires (4\%); and other disasters (7.7\%) [10].

University is one of the institutions that face the possibility of disaster. Apart from the geographical conditions that lead to disasters and natural states of emergency, this higher education institution has unique characteristics, which generally resemble a city with open and free access, changing population, unlimited operating time that is unlike companies, and scattered and diverse facilities (DOE, 2010).

In the last two decades, several disaster events have created negative impacts on universities. In 2015, a fire that destroyed a laboratory occurred in the University of Nottingham. In the same year, a student dormitory was also destroyed by a fire in the University of lowa. A fire in the University of the East-Manila, Philippines also occurred in 2016, causing a loss of 22 million PHP, or about 585 billion [2]. In Indonesia, there have been several cases of fire that occurred in Universities.

Universities need to change their short-term focus towards a sustainable and resilient approach. Resiliency is an important concept that has been developed in the field of disaster management, and it is a concept that emphasizes on building the adaptive capacity through the development of social capital, community competencies, and a strong communication and information system (National Research Council [NRC], 2009). Resilience has currently become a framework for improving preparedness, response, and recovery of the society or community in the short term, and adaptation to climate change in the long term (Cutter, 2014).

Students as a community that is often stay in campus for activities, learning, research, and organization activities face risks and dangers and it is important that they are prepared to deal with the possibility of disaster. 
This study aims to assess the awareness and preparedness of students in facing disasters and their response when a disaster occurs in an effort to become a resilient community.

\section{Literature Review}

\subsection{Vulnerability to disaster}

Disaster is an event or series of events that threaten and disrupt people's lives and livelihoods caused by both natural and/or non-natural factors as well as human factors that results in human casualty, environmental damage, property loss, and psychological impact (Law of the Republic of Indonesia No. 24, 2007). Paul [10] described disaster vulnerability as reduced capacity of individuals or groups to anticipate, cope with, resist, and recover from the effects of natural or man-made disasters. Vulnerability is most often associated with poverty, but also can occur when people are isolated, insecure, and helpless when dealing with risks or stress $[4,5,14]$.

To measure vulnerability, the determinants of how people or communities are exposed to disaster (= exposure) and how they are injured (= susceptibility) should be identified.

\subsection{Vulnerability to disasters on campus}

Over the past few decades, disasters have occurred in universities, interfering with frequency; causing injuries and even deaths; and disturbing learning, research, and public services provided by the universities. Damages to buildings and infrastructures have led to significant losses. Students as the subject is known to be affected to several factors that may increase their vulnerability to hazards. Those factors include: (1) Environmental Familiarity, (2) Life Experience, (3) Disaster Experience, (4) Financial Burdens, (5) Interrupted Social Networks, (6) Language Barriers, and (7) Cultural Differences $[1,6,16,18]$. 


\subsection{Resilience in facing disasters on campus}

Resilience is a transformative process to strengthen and improve the capacity of societies or communities of both women and men, institutions, and countries in anticipating, preventing and recovering and transforming from shocks, stress and changes [17].

\subsection{Disaster management}

FEMA (2003) describes four phases in identifying and implementing actions to reduce disaster losses on campus, namely: (1) Phase 1-organizing resources; (2) Phase 2hazard identification and risk assessment; (3) Phase 3-developing disaster mitigation plans; and (4) Phase 4-adoption and implementation [3].

\subsubsection{Pre-disaster}

Pre-disaster management includes disaster mitigation, preparedness, and early warning.

1. According to FEMA, mitigation is any cost-effective action which is used to eliminate or reduce the risk of loss of life and property damage from hazards or natural disasters, and technology. Disaster mitigation can be done through a technical, human, administrative, and cultural approaches [3].

2. Preparedness is the level of vigilance and readiness of individuals and communities to deal with future disasters, such as making a disaster plan, trying out and simulate disasters, providing signs of danger, communicating to the public about the vulnerabilities and actions that must be performed to reduce vulnerabilities and evacuation [10]. Building preparedness is an important element and the most strategic phase as it will determine the resilience of the community in facing disaster threats $[3,11]$.

3. Early warning is given to enable the implementation of prompt actions in order to reduce the risk of disasters and prepare for emergency responses. 


\subsubsection{Emergency response}

Emergency response is a series of activities carried out immediately upon occurrence of disaster to deal with negative impacts, including victim, wealth, or property rescue and evacuation; fulfil basic needs; rescue; and infrastructure and facility recovery [14]

\subsubsection{Post-disaster}

Post-disaster management includes post-disaster reconstruction and rehabilitation phase as well as repairing and restoring of all aspects of public or community services to an adequate level in post-disaster areas with the main objective to normalize or implement normal aspects of government and community life in post-disaster areas [15].

\subsection{Determinants of student awareness level in facing disaster}

A study conducted by Gerdan [4] classified the determinants of individual awareness level based on the followings:

1. Age, Gender

By age group, the oldest age group (26-30 years) has the highest awareness level than other age groups. However, there is no significant difference between men and women.

2. Grade

Based on findings of the study, there is a relationship between grades and the level of awareness where students with higher grade has a higher level of awareness.

3. Experience in Dealing with Disaster

It is noted that there is a relationship between the experience of dealing with catastrophic events and the student's level of consciousness, but there is no relationship between the impact of the disaster experience and the behavioral level.

4. Training

It is revealed that there is a relationship between the disaster training performed by students and the level of awareness. 


\section{Research Method}

This was a quantitative cross-sectional study involving a total of 388 students of the School of Health Sciences of University of Indonesia that consisted of undergraduate students of the Faculty of Medicine, Faculty of Dentistry, Faculty of Nursing, and Faculty of Pharmacy. The sampling was performed using the selective purposive sampling method. The questions asked were closed-ended questions with yes/no answers, multiple choice items, and several open-ended questions.

As an example of the closed-ended question, the respondents were given the questions on whether they feel the campus has any potential disaster, whether they have done any disaster preparation. As for the multiple choice items, respondents could choose one or more answers such as the kinds of preparation done. The options were: keep emergency contacts, prepare a disaster kit, or seek information on the preparations made. For open-ended questions, the example was the question on what actions they should take in case of a disaster on campus.

The results took the form of a total of each independent variable which were categorized into two category groups with a mean/median score limit of $\leq 5$ as not resilient and $>5$ as resilient.

\section{Results}

Of the 388 respondents, 76 percent females and 24 percent males participated in this study. The respondents were from the Faculty of Medicine (39.2\%), Faculty of Dentistry (20.6\%), Faculty of Nursing (18\%), and Faculty of Pharmacy (22.2\%). As seen in Table 1,58 percent of these students have had experienced disaster before.

\subsection{Preparedness in facing disasters}

Only 45.1 percent of respondents had done preparations to face disasters (Table 2). Results showed that respondents who had experienced catastrophic event were more likely to have done a lot of preparations to cope with disasters (46\%) and students who had never experienced any disaster answered $44 \%$.

The level of awareness towards potential disasters on campus was 77 percent with respondents stated that campus had disaster risks. The results showed that the level of awareness towards potential disasters on campus was higher among students who 


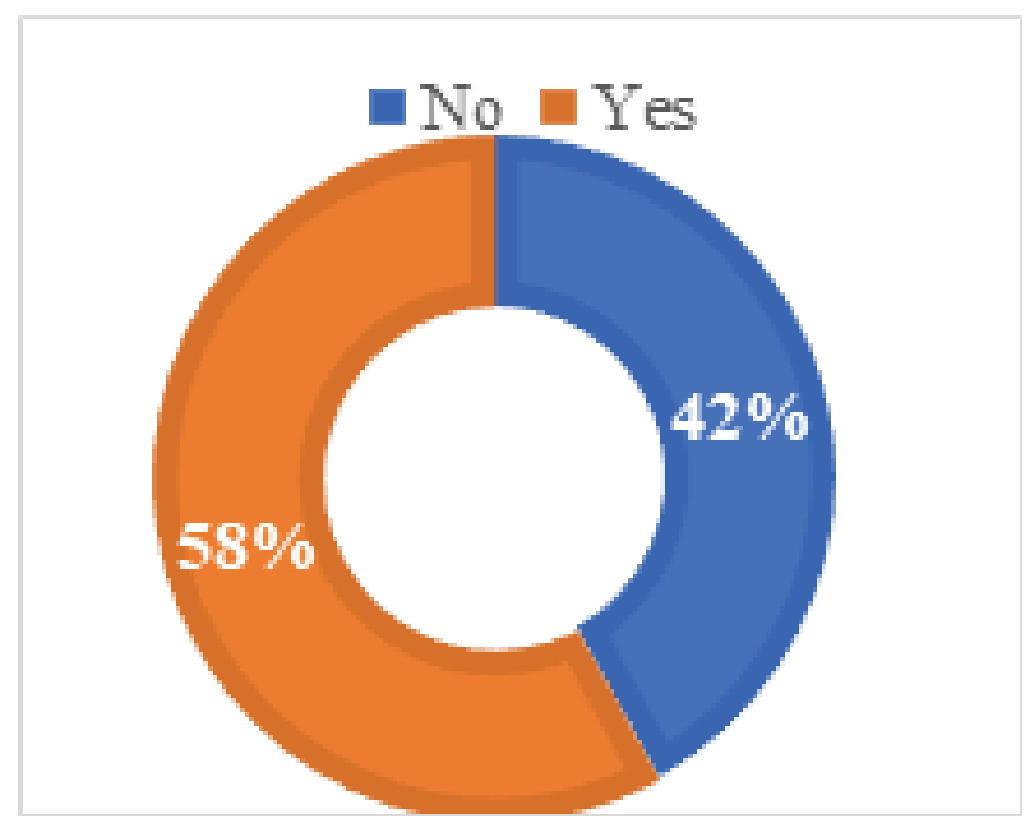

Figure 1: Distribution of students by disaster experience.

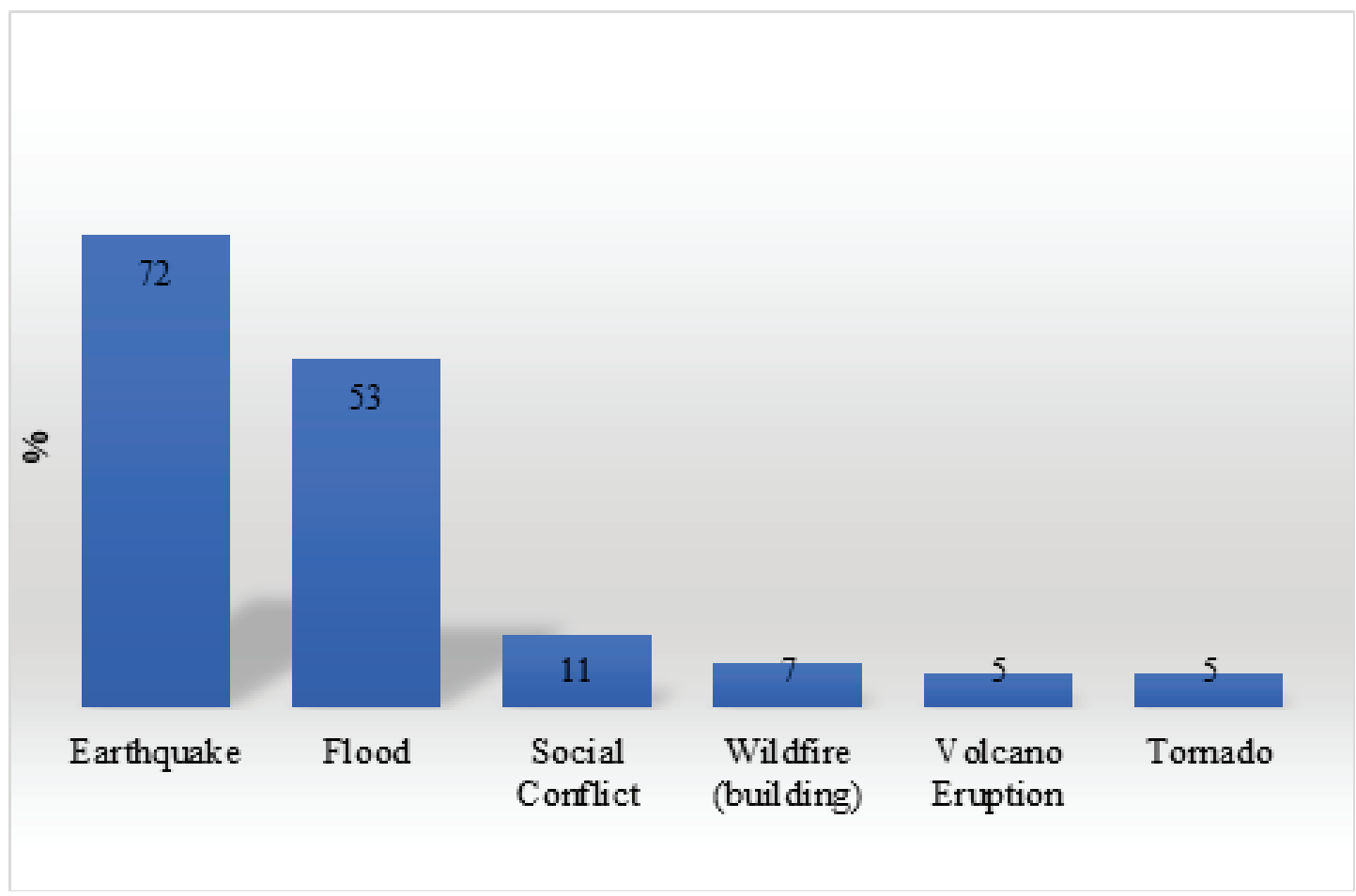

Figure 2: Type of disasters most frequently experienced.

have experienced previous disaster event, which was up to 82 percent (185 respondents), while the level of awareness towards potential disasters on campus among students who have never experienced any previous disaster was 70 percent (114 respondents). The purpose of this question was to state that universities as an institution has 


\section{Not prepared yet $\mathrm{E}$ Has prepared}

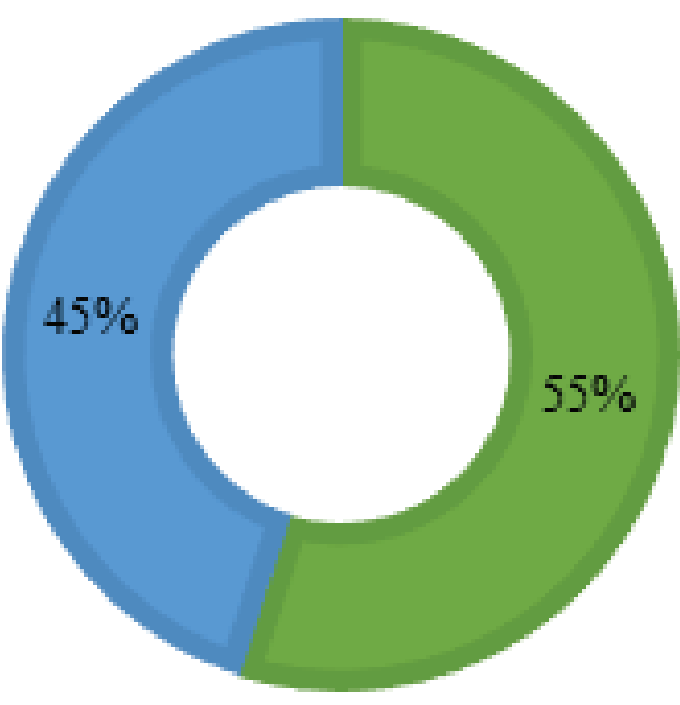

Figure 3: Distribution of student by preparation in facing disasters.

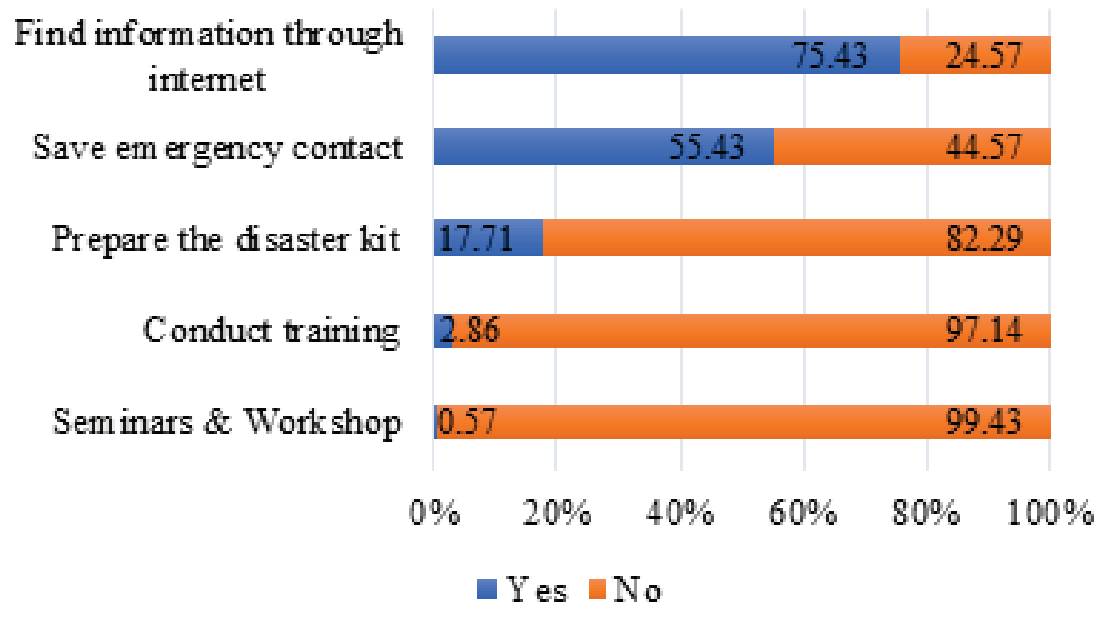

Figure 4: Types of preparation performed.

not escaped disasters and in the last two decades, disaster events have been reported in universities in this country as well as in other countries.

Ninety six percent of respondents stated that awareness to do preparation in facing disasters on campus is necessary.

For questions regarding the level of knowledge on early warning systems applied on campus, only 21.9 percent of respondents stated that they know about the presence 


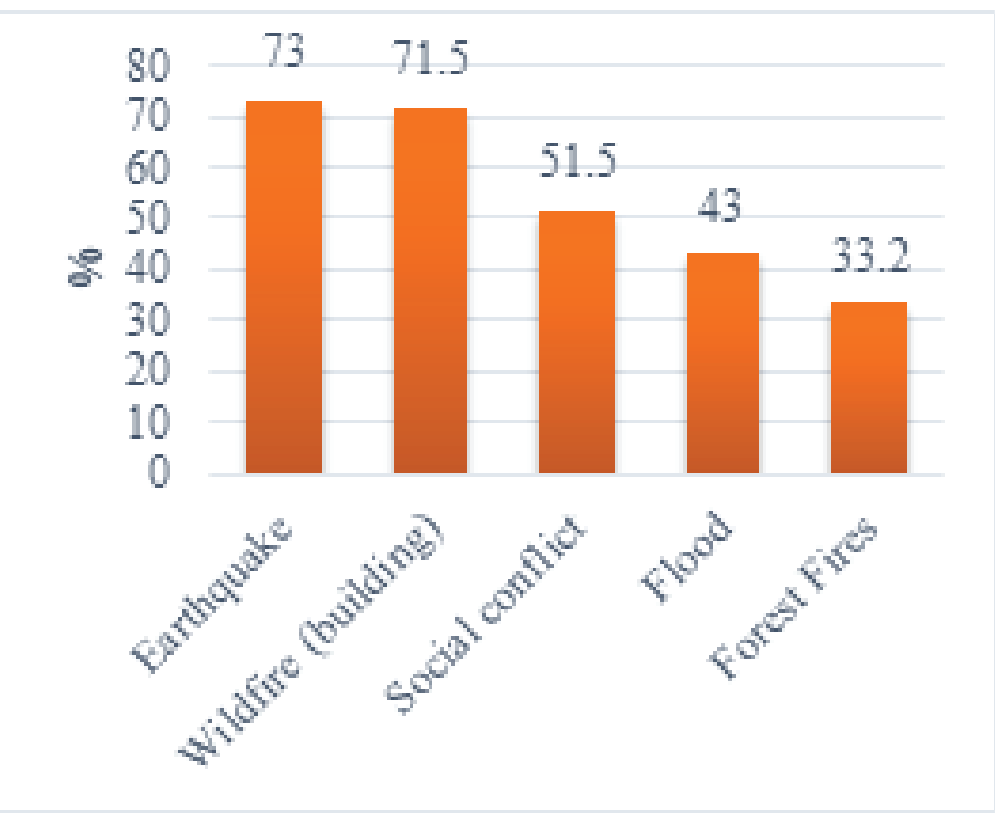

Figure 5: 5 potential disaster events on campus based on students' perception.

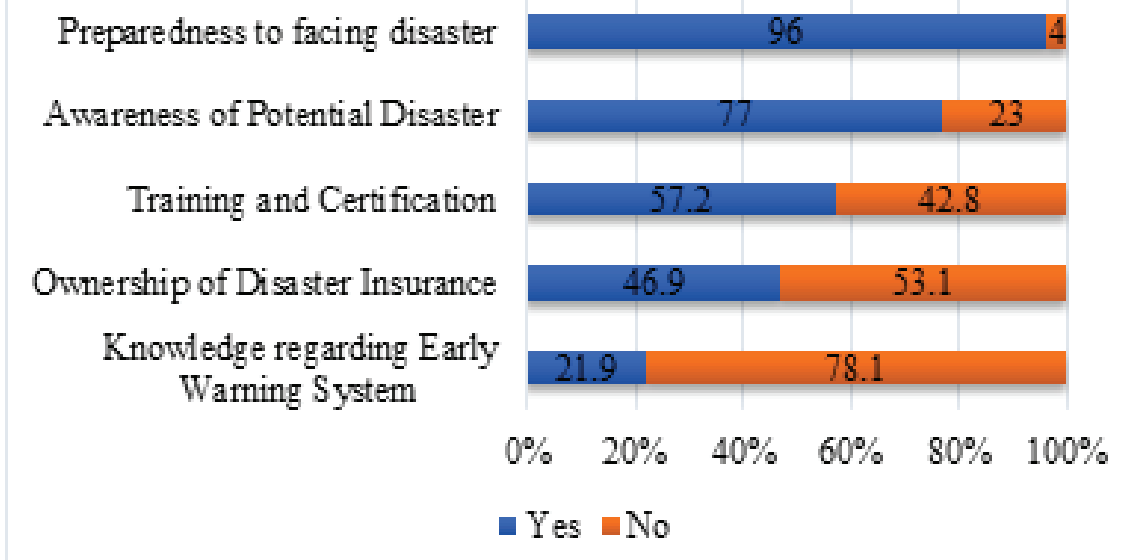

Figure 6: Early warning system and disaster mitigation.

of some types of available early warning system, including emergency alarm, smoke detector, evacuation signs/emergency staircase, announcement by intercom, sprinkler, fire extinguisher, and hydrant.

The sources of disaster-related education/information were mostly news from TV, radio, or online news. However, many respondents also stated that they obtained disaster-related information from social media, as depicted in Chart 8.

In terms of disaster training/simulation participation, 57.2 percent had received/ participated in disaster-related training/simulation. The majority answered that they did simulation as a part of a course module at the faculty (38\%). Because this is a mandatory lecture, most students did simulation based on the module. The simulation 


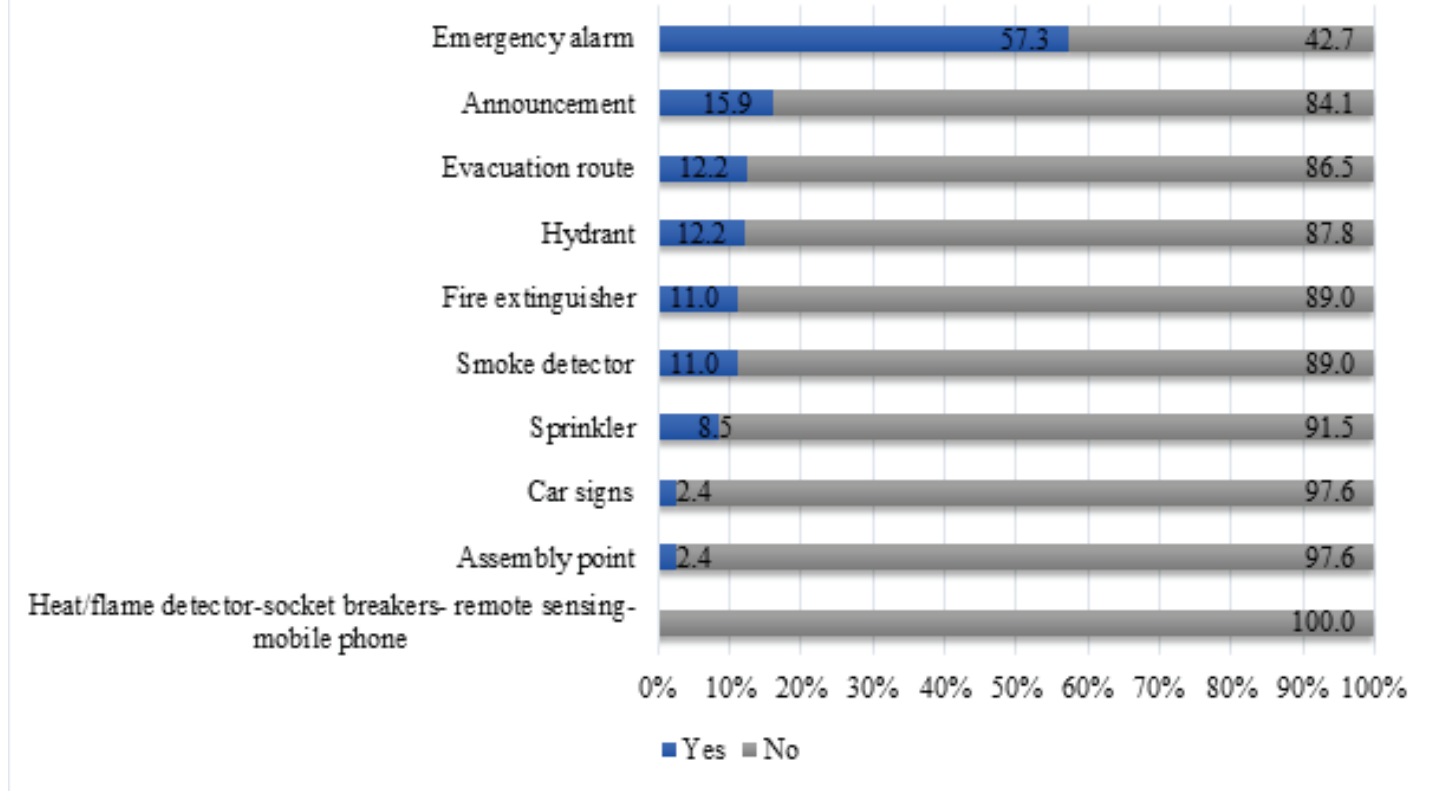

Figure 7: Respondent's knowledge based on type of early warning system on campus.

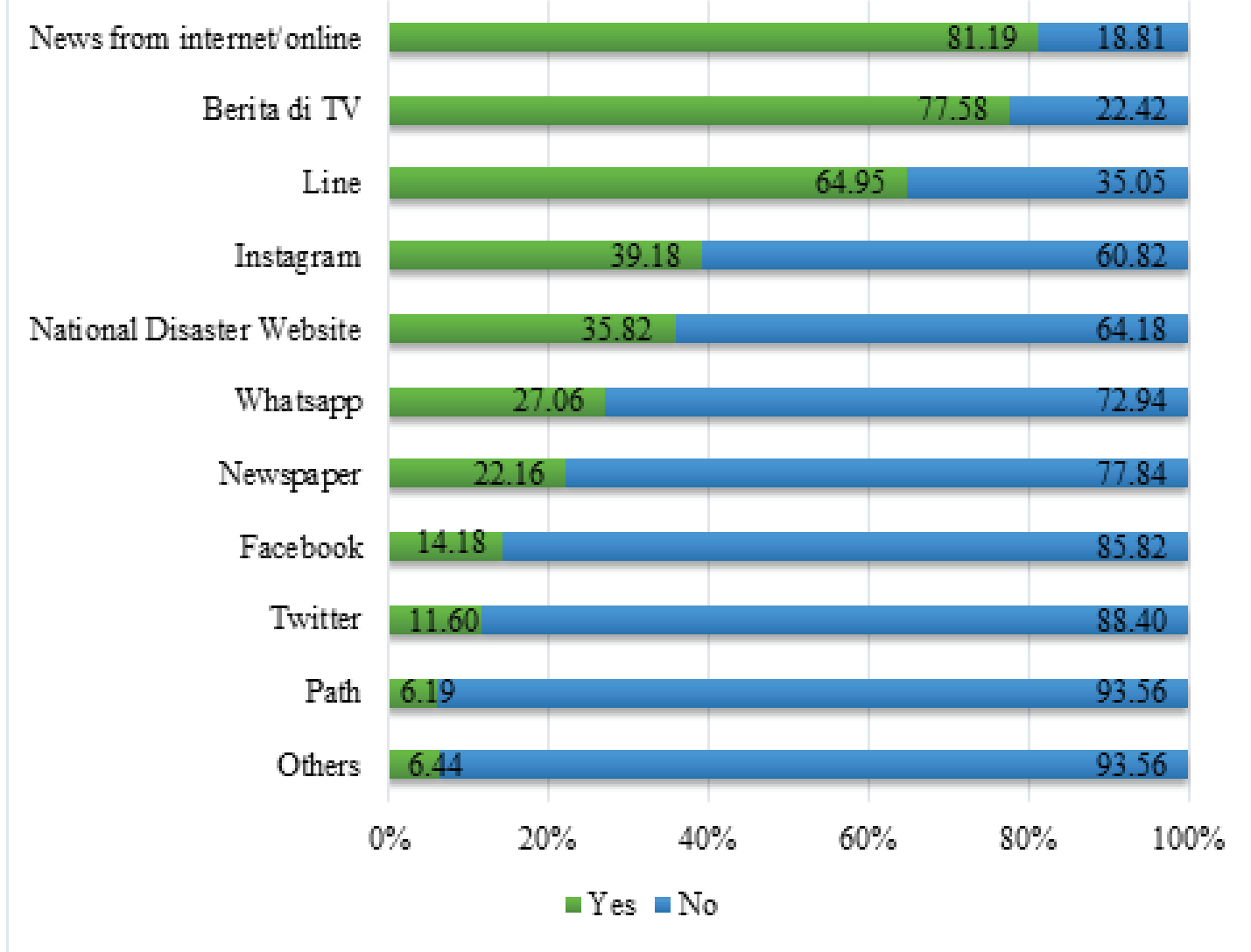

Figure 8: Source of information/education related to disasters.

exercises included in the lecture were simulations on earthquake and fire, how to use fire extinguisher, and training in Basic Life Support. 


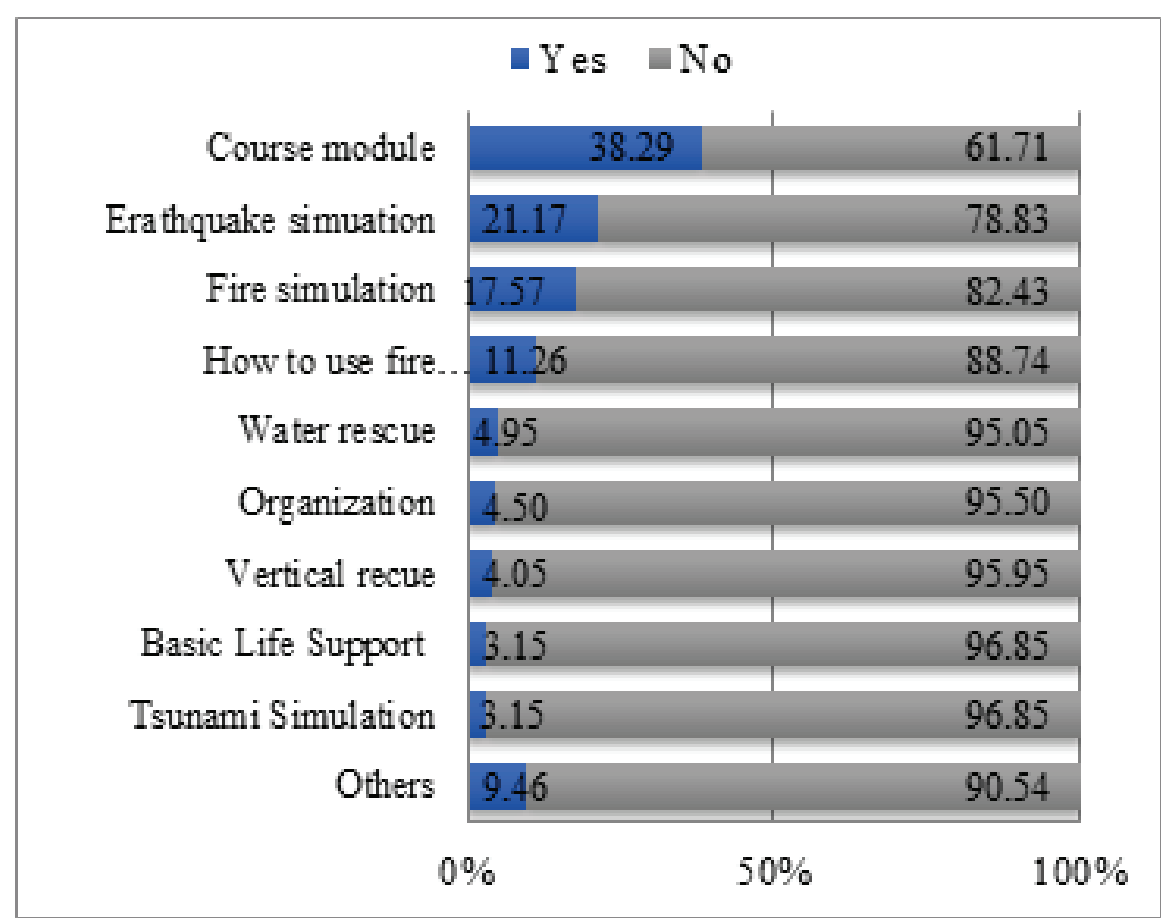

Figure 9: Type of disaster-related training/simulation.

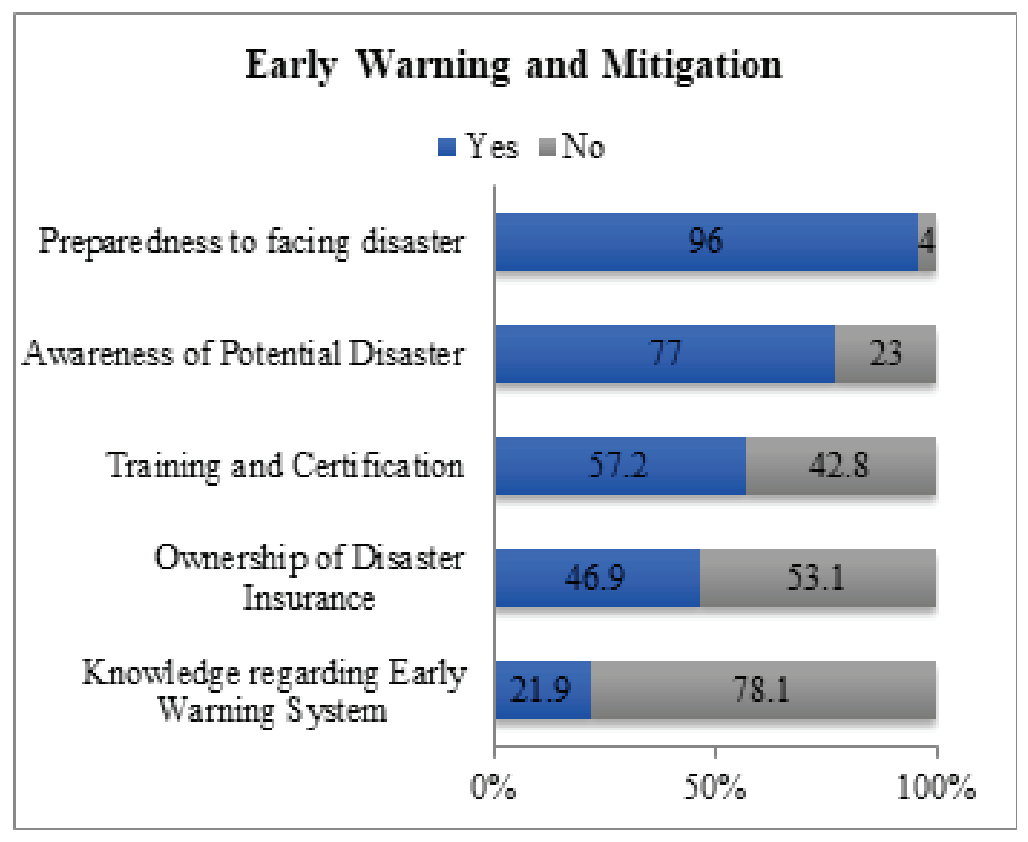

Figure 10: Pre-disaster variables.

The insurance ownership levels had not reached half of the respondent population, of which 46.9 percent had a disaster-related insurance. 


\subsection{Emergency response}

Of 388 respondents, 56.4 percent stated that they were less prepared for disasters, while 10.3 percent stated that they were not prepared at all for the disaster. A 30.9 percent felt quite ready, 2.3 percent felt ready, and o percent said they were ready. Through the open-ended questions about emergency responses in the case of disasters on campus, students, on average, had taken appropriate emergency response actions. However, there were some respondents who answered that they would panic if a disaster occurred.

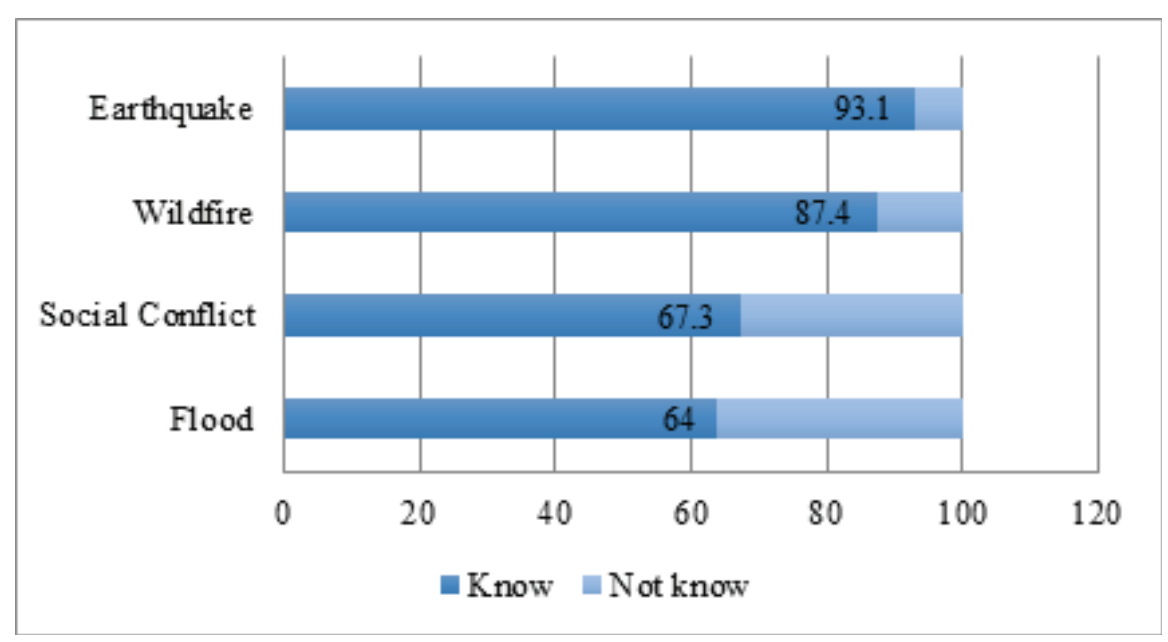

Figure 11: Emergency response during disaster.

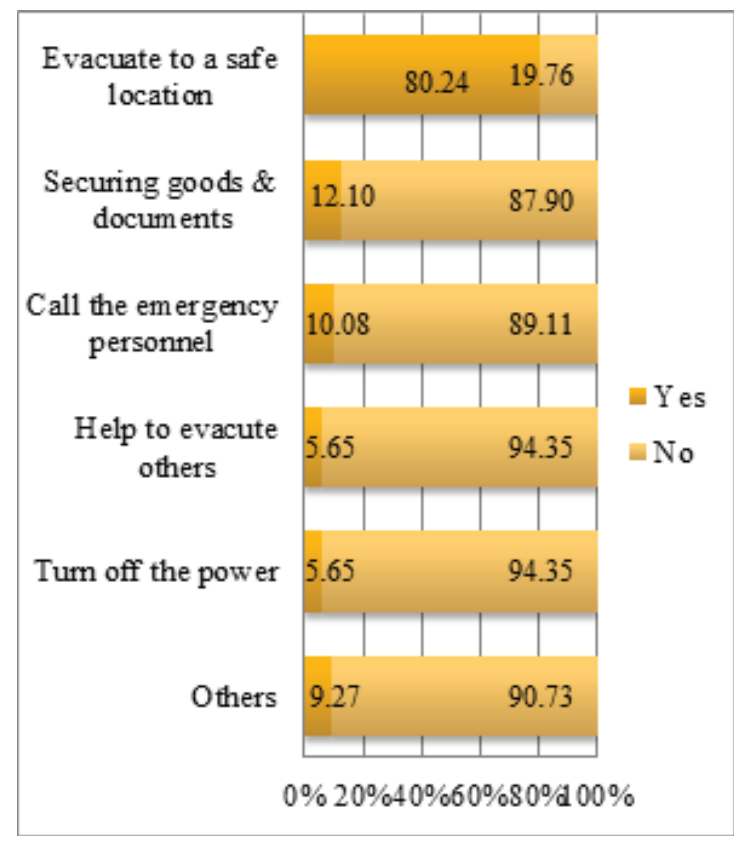

Figure 12: Emergency response to flood. 


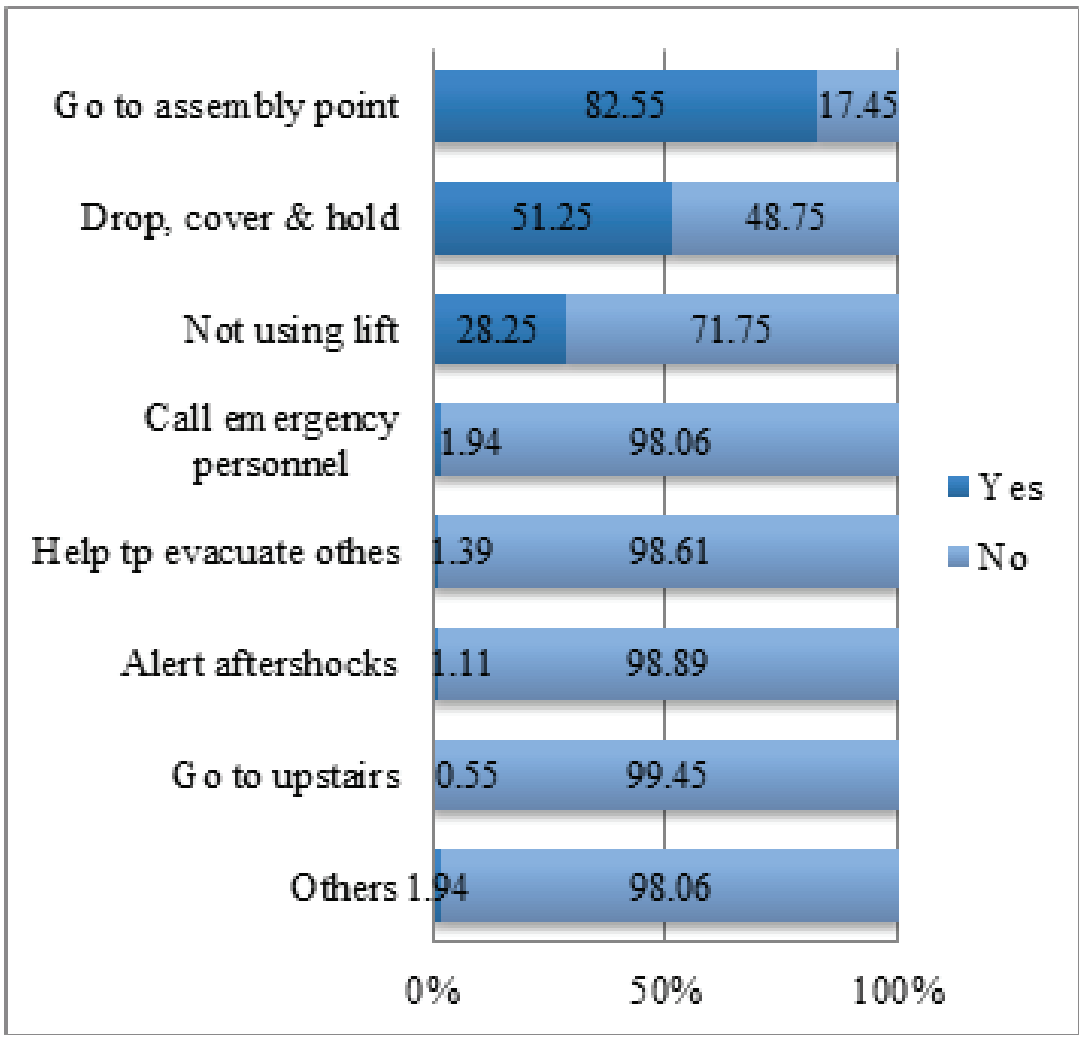

Figure 13: Emergency response to earthquake.

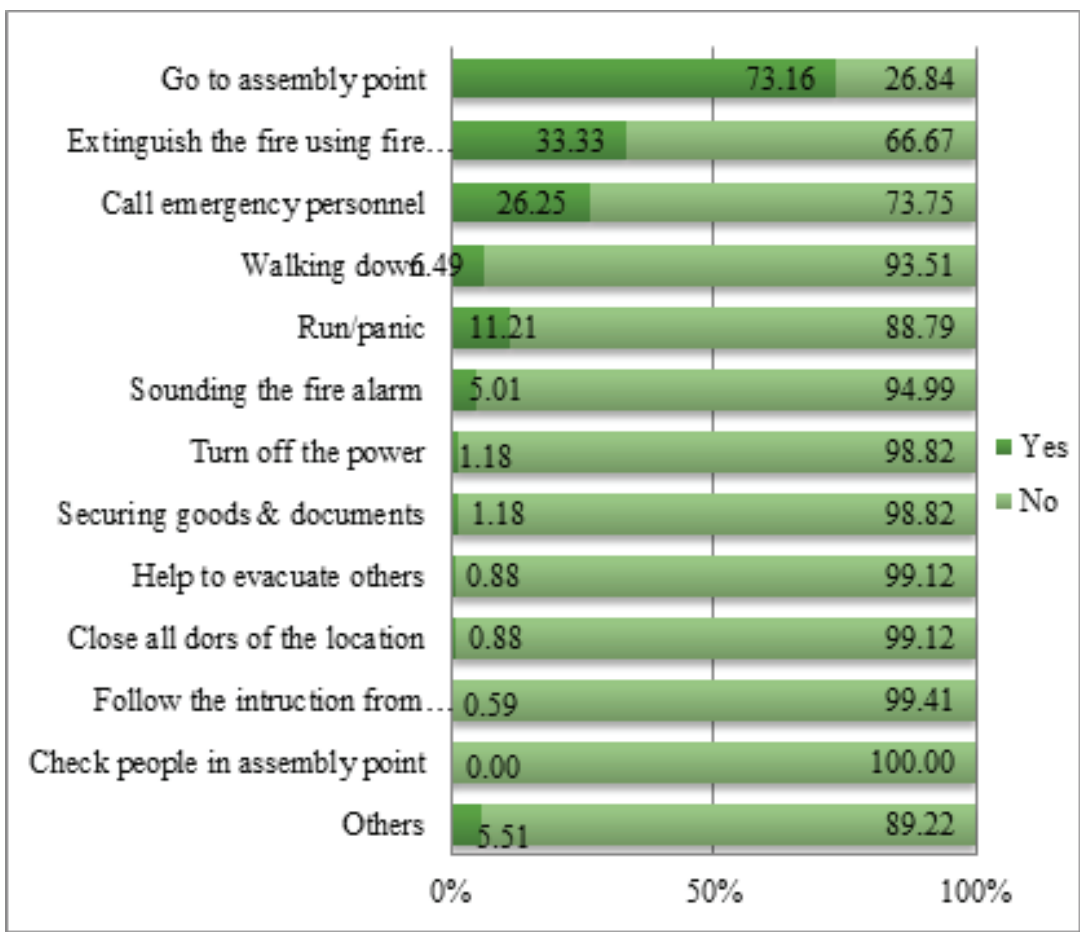

Figure 14: Emergency response to fire conflict. 


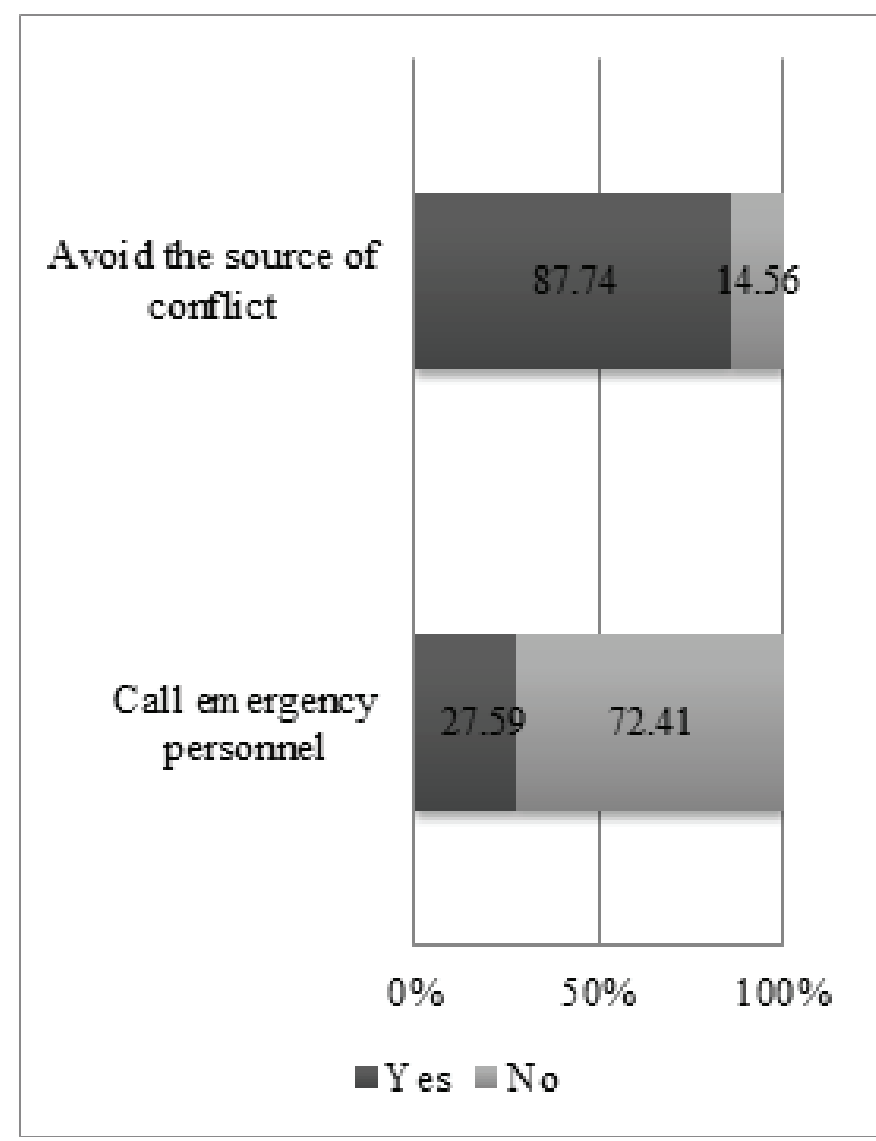

Figure 15: Emergency response to social.

\subsection{Post-disaster}

A total of 95.4 percent of respondents knew the location of the nearest clinic in the campus area.

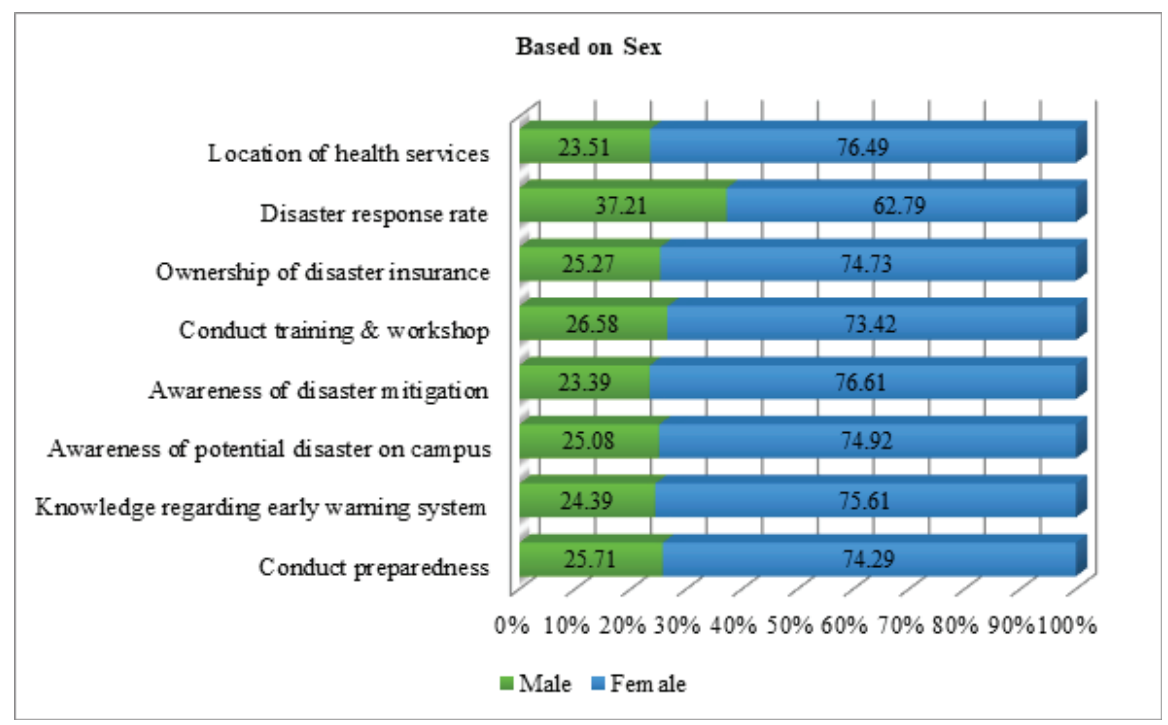

Figure 16: Demographic distribution of respondents against independent variables. 

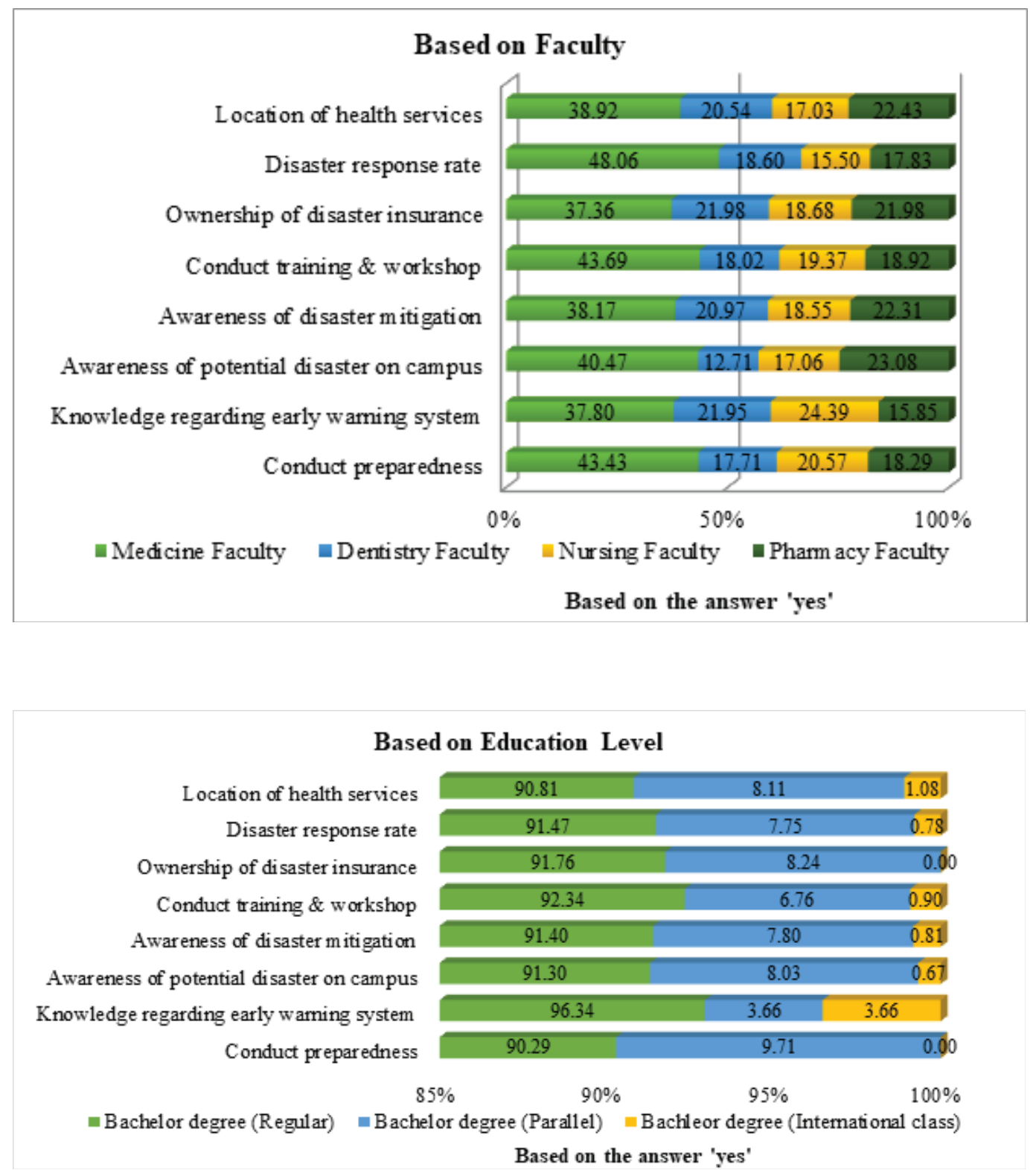

\section{Discussion}

\subsection{Disaster preparedness}

Disaster preparedness is one of the disaster management efforts where the community should prepare for possible disasters [5]. Paul [10] stated that preparedness is the level of awareness and readiness of individuals and communities to face future disasters that includes efforts like disaster planning, disaster try-out and simulation, hazard signs, public communication about vulnerabilities and actions to reduce them, evacuation, emergency response exercises, and emergency medical training [10]. 

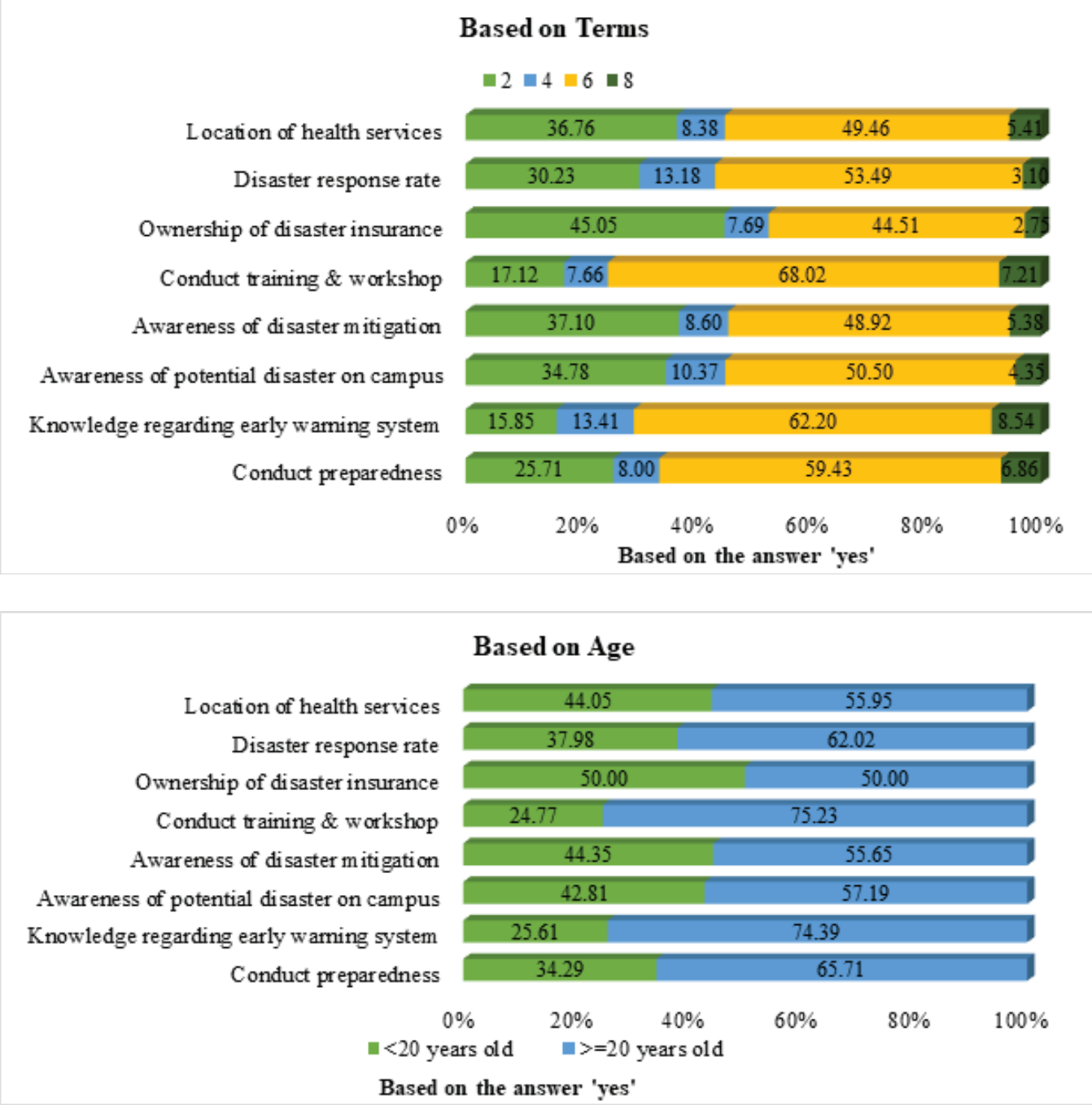

Many methods that can be applied to raise the awareness in the community, such as a human approach aimed at forming a community or society that understand and is aware of hazards that, hopefully, the people and community will be ready and resilient in facing disaster events. Another method is the cultural approach, which is performed to raise awareness of the community on the concepts and efforts made in dealing with disasters that are adapted to local wisdom [14]. Through these approaches, it is expected that the public will receive and apply the concept of disaster management [14].

The early warning system is a combination of tools and processes inherent in the institutional structure. Early warnings are established for rapid and appropriate actions in order to reduce disaster risks and prepare for emergency response measures. When a person has a high level of knowledge on the types of early warning system, he or she is expected to take actions as quickly and accurate as possible when dealing with disasters. In addition, a person who knows the type and function of early warning 
systems can also reduce the risk of negative impacts due to a disaster event because he or she can inform the community on the disaster hazards.

Training needs to be conducted as an effort to increase capacity, speed, and preparedness in overcoming disaster, both individually and as a community. Kapucu [8] explained that in addition to simulation, the types of training to be conducted by a campus can take the form of a discussion or a meeting where participants are given disaster scenarios and they must write the response they should give to deal with them [18].

Disaster insurance ownership is one of the disaster mitigation efforts because it can transfer individual risks, including disaster risks. In addition, insurance ownership has the objective to enable rehabilitation and reconstruction of damages after a disaster that causes damages and losses.

\subsection{Emergency response}

Emergency response is a series of activities carried out immediately upon the occurrence of a disaster to deal with negative impacts, including rescue and evacuation of victims, possessions or property, fulfillment of basic needs, rescue, and facility and infrastructure recovery. Auletta [1] explained that there has been no recent attempt to assess the perceived danger of students on disasters even though the university itself has disaster risks. Nevertheless, in some universities, every two years students participate in the National Educational Benchmarking Inc. where students are asked about their awareness and safety [1]. Preparedness for disasters is important because it can reduce vulnerability to disasters, both by mapping the possible risks of disasters, building existing resources in the community, as well as establishing formal institutions [10].

Auletta [1] also described that students are subjects that are known to be a factor that may increase vulnerability to hazards. Such factors include: 1) Environmental Familiarity, 2) Life Experience, 3) Disaster Experience, 4) Financial Burdens, 5) Interrupted Social Networks, 6) Language Barriers, and 7) Cultural Differences [1].

The successful response to disaster is needed by the community/society and health care system that includes, among others:

1. Explanation and anticipation for disaster risks and hazards,

2. Preparation of material resources and skilled personnel to provide responses related to the risks and hazards, 
3. Development a comprehensive plan to implement the resource,

4. Learning from disaster events to strengthen preparedness for future disasters [14].

\subsection{Post-disaster}

Post-disaster is an event after a disaster occurs and after the emergency response process is finished, that is, whole system recovery in the form of managing volunteers and in-kind donations, assessing damage, providing emergency assistance, rehabilitating injured victims, providing temporary shelter, and recover systems to normal. In this study, the post-disaster phase was assessed in the form of student's knowledge of the location of the nearest clinic in the area of the campus. It is aimed to ensure that respondents know the location of the nearest health service to provide medical assistance to the affected victims after the occurrence of a disaster.

\section{Conclusion}

In general, students of the School of Health Sciences, University of Indonesia are resilient enough to face disasters. It is based on the percentage of respondents' answers to all questions, the answers that have a score $>50 \%$ are categorized as resilient in facing of disasters $[1,6,15]$, there are: (1) 77 percent of respondents are aware of potentials for disaster on campus; (2) 96 percent respondents feel the need to prepare to facing disasters, (3) Source information related to disasters obtained by students have been based on valid sources; (4) 57.2 percent participants have been trained in disaster; (5) Respondents give appropriate answers for emergency response to flood disaster $(64 \%)$, earthquake (93.1\%), fire (87.4\%), and social conflict $(67 \%)$; and knowledge about clinic location in high campus area, that is equal to 95.4 percent. It is aimed at the occurrence of disaster on the campus, respondents know the location of the nearest health service to provide medical assistance to the affected victims.

In addition, there are some improvements that need to be done due to low preparedness level (45.1\%), low knowledge on early warning systems on campus (only $21.1 \%$ respondents know about early warning system types), lack of disaster insurance ownership ( $46.9 \%)$, low level of disaster response, and the fact that some respondents provide inaccurate answers to the emergency response variable such as 11 percent of respondents will be panic during fire disaster in campus and some respondents tried 
to extinguish the fire using water, but not all types of fires can be extinguished with water, as some react with water.

\section{Recommendations}

To increase the capacity of students, a number of measures should be implemented such as (1) more than one disaster simulation for students. Most of the disaster simulations are performed based on course modules. Implementation of simulation/training can be performed using a table top approach where students are given a disaster scenario and provide answers regarding actions that should be taken by them; (2) the disaster management course module managing team should divide the students to facilitate the absorption of information and knowledge given to the students. In addition, more emphasis should be placed on the pre-disaster stage (disaster preparedness and mitigation) as the study shows a low percentage in the findings. One way to do this is to do direct practice or simulation by creating role plays on how to do community disaster management, starting from preparing the available resources, preparing emergency response procedures, providing risk information/communicating risks to others; (3) the faculty should provide information on disaster risk reduction (disaster mitigation, early warning systems on campus and the locations, evacuation routes, and emergency responses) both through announcements or intercom, media, message broadcast, and faculty website. Information should be provided regularly that all students, especially freshmen, know about the information; (4) students or student organizations should be involved in disaster mitigation planning to increase the capacity to cope with disaster.

Students should also make some improvements, such as (1) increasing participation of student organizations in conducting disaster risk reduction on campus, such as establishing a regular discussion forum where student organizations involve students or even staff on campus to raise awareness and disaster preparedness on campus, holding disaster-related training, holding small-scale disaster simulation activities, and providing routine information on disaster risk reduction through posters or social media of the student organizations; (2) sharing information on disaster risks; and (3) taking into account the validity of information obtained from social media, because some sources cannot be verified. 


\section{Conflict of Interest}

The authors hereby declare that they have no significant competing financial, professional, or personal interests that might have influenced this manuscript.

\section{Acknowledgment}

This research was supported by University of Indonesia, Faculty of Public Health. The author highly appreciated to Faculty of Medicine, Faculty of Dentistry, Faculty of Nursing, and Faculty of Pharmacy of the University of Indonesia, and Occupational Health and Safety Department University of Indonesia who provided insight and expertise that greatly assisted the research.

\section{Study Limitation}

This study was conducted to explore the students' perception in facing disasters as an effort to enhance the resilience in dealing with disaster and not to see the relation between variables. Other limitations of the study are this study was conducted on respondents who attended the even semester, no in-depth interviews were performed (limited to open- and closed-ended questionnaires), no effort was made to link the level of knowledge to disaster preparedness in the first semester, and no observation on infrastructures of the study site was performed.

\section{References}

[1] Auletta, J. L. (2012). Disaster Vulnerability of University Student Populations. Graduate Thesis, University of South Florida, pp. 3, 7-11, 52-56, 106-115.

[2] Corrales, N. (2016). Fire hits university of the East-Manila. Retrieved from http:// newsinfo.inquirer.net/777478/fire-hits-university-of-the-east-building (accessed 13 March 2017).

[3] Federal Emergency Management Agency. (2003). Building a Disaster-resistant University, pp. 5, 21, 29, 35-38.

[4] Gerdan, S. (2014). Determination of disaster awareness, attitude levels and individual priorities at Kocaeli University. Eurasian Journal of Educational Research, กo. 55, pp. 160-161, 165-169. 
[5] Hermann, J. (2007). Disaster Response Planning \& Preparedness: Phases of Disaster, p.11-13.

[6] How, V., Peter, P., Martinus, K. B., et al. (October 2015). A case study of campusbased initiatives to disaster awareness program: The road to resilience. Open Access Library Journal, vol. 2, no. 10.

[7] International Federation of Red Cross and Red Crescent Societies. (2011). Public Awareness and Public Education for Disaster Risk Reduction: A Guide. Geneva, Switzerland: International Federation of Red Crossand Red Crescent Societies.

[8] Kapucu, Naim dan Sana Khosa. (2012). Disaster resiliency and culture of preparedness for university and college campuses, pp. 4-5, 7-32. Orlando: University of Central Florida.

[9] dan Schultz, K. (2010). Disaster Medicine: Comprehensive Principles And Practices. New York, NY: Cambridge University Press.

[10] Paul, B. K. (2011). Environmental Hazards and Disaster. USA: Kansas State University.

[11] Pearson, L. (2012). Early Warning of Disasters: Facts and Figures.

[12] Pfefferbaum, R. L., Pfefferbaum, B., and van Horn, R. L., et al. (2013). Communities Advancing Resilience Toolkit (CART): The CART Integrated System. University of Oklahoma Health Science Center.

[13] Preston, J. (2012). Chapter 1: What is disaster education? in Disaster Education. Race, Equity and Pedagogy. Netherlands.

[14] Ramli, S. (2010). Pedoman praktis manajemen bencana. Jakarta: PT. Dian Rakyat.

[15] Ringo, Z., Luvinga, K., Morsardi, L., et. al. (2016). The ability to use and respond early warning system installations: Insights from higher learning institutions in Dodoma municipality. International Journal of Modern Management Sciences, vol. 5, no. 1, pp. $1-14$.

[16] United Nations Development Programme. (February 2014). Disaster Resilience Measurements: Stocktaking Ongoing Efforts in Developing Systems for Measuring Resilience.

[17] Yosafat, F. E., Rohman, A., Widjaja, D. W., et al. (2012). Vulnerability and capacity assessment anticipating the earthquake hazard from lembang fault: A case study of Bandung Institute of Technology, West Java, Indonesia. Journal of Disaster Research, vol. 7, no. 6 .

[18] Zaboli, R., Seyedin, S. H., Malmoon, Z. (2013). Early warning system for disasters within health organizations: A mandatory system for developing countries. 
Health Promotion Perspectives, vol. 3, no. 2, pp. 261-268. Retrieved from https: //www.ncbi.nlm.nih.gov/pmc/articles/PMC3963676/pdf/hpp-3-261.pdf 